\title{
El tratamiento de la temática padre e hijo en cuentos de Borges y Rulfo
}

\section{O tratamento da temática pai e filho em contos de Borges e Rulfo}

\author{
Altamir Botoso ${ }^{1}$
}

DOI: $10.19177 /$ memorare.v8e12021236-246

\begin{abstract}
Resumen: Un mismo tema permite tratamientos distintos y variadas interpretaciones. Las relaciones entre padres e hijos, por ejemplo, se llenan de significados y símbolos matizados por aspectos realistas, fantásticos o mágicos en el ámbito literario. Basados en estas ponderaciones, en este artículo, nuestra propuesta es analizar los cuentos "Las ruinas circulares" del escritor argentino Jorge Luis Borges y "No oyes ladrar los perros" del mexicano Juan Rulfo, a partir de una mirada comparatista, destacando el modo como estos dos autores exploran el tema de las relaciones entre padres e hijos en la ficción. Borges se vale de lo fantástico para tratar la cuestión de paternidad en el cuento, mientras Rulfo se utiliza del realismo para poner de relieve el dolor y la desesperanza de padre e hijo en tierras latinoamericanas. El aporte teórico se basa en los estudios críticos de Sainz Borgo (2018), Sánchez Quintana (2016), Díez R. (2016), Gnutzmann (1972), Katra (1990), Lasarte (1989), Oviedo (2012), Vargas (2003).
\end{abstract}

Palabras clave: Cuento. Paternidad. Literatura latinoamericana. Realismo mágico.

Resumo: Um mesmo tema permite diferentes tratamentos e variadas interpretações. As relações entre pais e filhos, por exemplo, são repletas de significados e símbolos matizados por aspectos realistas, fantásticos ou mágicos no âmbito literário. Pautados por essas ponderações, neste artigo, nossa proposta é analisar os contos "Las ruinas circulares" do escritor argentino Jorge Luis Borges e "No oyes ladrar los perros" do mexicano Juan Rulfo, a partir de um viés comparatista, destacando a maneira como esses dois autores exploram o tema das relações entre pais e filhos na ficção. Portanto, nota-se que Borges usa o fantástico para tratar da questão da paternidade no conto, enquanto Rulfo usa o realismo para evidenciar a dor e o desespero de pai e filho em terras latino-americanas. 0 suporte teórico centra-se nos estudos críticos de Sainz Borgo (2018), Sánchez Quintana (2016), Díez R. (2016), Gnutzmann (1972), Katra (1990), Lasarte (1989), Oviedo (2012), Vargas (2003).

Palavras-chave: Conto. Paternidade. Literatura latino-americana.

\footnotetext{
1 Doutor em Letras, área de Teoria Literária e Literatura Comparada pela Universidade Estadual Paulista Júlio de Mesquita Filho, Unesp, Assis-SP e docente do curso de Letras/Espanhol e do Mestrado em Letras da Universidade Estadual de Mato Grosso do Sul, UEMS, campus de Campo Grande-MS. E-mail: abotoso@uol.com.br.
} 


\section{Introducción}

He aprendido que cuando un recién nacido aprieta con su pequeño puño, por vez primera, el dedo de su padre, lo tiene atrapado por siempre.

Johnny Welch

Puesto que en la literatura, de distintos países, un mismo tema recibe tratamientos diferentes, este artículo, busca analizar y comentar la manera como Jorge Luis Borges y Juan Rulfo construyen la temática de las relaciones entre padre e hijo en dos cuentos: "Las ruinas circulares", del primero y "No oyes ladrar los perros", del segundo.

Con relación a las figuras paternas y los conflictos con los hijos, Karina Sainz Borgo (2018, s. p.) afirma que:

La figura del padre atraviesa la literatura desde su origen. El rey Príamo, roto de dolor, que se presenta ante Aquiles pidiéndole de vuelta el cadáver de su hijo Héctor para darle al fin sepultura. El 'papá Goriot' de Balzac, ese hombre apartado y rechazado por sus hijas. El fantasmagórico rey Hamlet que ronda la orfandad del joven príncipe de Dinamarca en la tragedia de Shakespeare. El padre: esa larga y extraña sombra que marcó la vida y la obra de autores como Dickens o Kafka y mucho más cercanos en el tiempo, como a Philip Roth, Richard Ford, Mario Vargas Llosa, Héctor Abad Faciolince o Marcos Giralt Torrente, quienes han acometido libros memorialísticos. Nadie sale ileso de un padre vivo, mucho menos de uno que se ha marchado.

De acuerdo con la autora las relaciones entre padres e hijos, en el ámbito ficcional, se revelan difíciles, problemáticas, tortuosas, llenas de dolor y marcadas por desilusiones y conflictos a veces insuperables.

A la figura del padre se han dedicado las páginas más hermosas y terribles de la literatura universal. Hubo padres cuya crueldad fue infinita, dentro y fuera de los libros. Los hubo violentos y alcohólicos, como el de Huckleberry Finn o tiránicos como en el Falkner de Mary Shelley; también de carne, hueso y abrasadora frialdad, como Herman Kafka, aquel comerciante textil a quien nada le pareció jamás lo suficientemente bueno y que hizo sentir a su hijo, Franz Kafka, como un insecto o un hombre obligado a defenderse sin saber de qué se le acusa. Toda paternidad entraña una grieta. Acaso porque ninguna relación de trasferencia de vida ha conseguido escapar de la fractura. Dar amor y recibirlo puede llegar a ser el mayor de los desastres. [...] (SAINZ BORGO, 2018, s. p.).

La paternidad, vista desde distintos ángulos, es un tema que recibió mucha atención por parte de los escritores de la antigüedad hasta los días de hoy, y pone de manifiesto como pueden ser problemáticas las relaciones entre padres e hijos a lo largo de la existencia humana.

Basados en esa premisa, nuestro objetivo es analizar los dos cuentos mencionados, subrayando la diferencia que se nota en el tratamiento de la temática padre e hijo, ya que en Borges se verifica el aporte del fantástico en el cuento, para plasmar una vida que se extiende hasta el infinito, y en Rulfo, hay un realismo crudo en el que el dolor, el desespero y la violencia contamina a los personajes y llega a destruirlos.

En suma, nuestro enfoque abarca un estudio comparado de los personajes protagonistas y su actuación en los dos textos seleccionados, 
de esos dos grandes escritores de la literatura latinoamericana contemporánea.

\section{Creador y criatura en "Las ruinas circulares"}

El escritor Jorge Luis Borges nació en Buenos Aires, en 24 de agosto de 1899, y murió en Ginebra, Suiza, en 14 de junio de 1986. Fue poeta, cuentista y ensayista. Estudió en Ginebra e Inglaterra. Vivió en España desde 1919, hasta su regreso a Argentina en 1921. Colaboró en revistas literarias, francesas y españolas, donde publicó ensayos y manifiestos.

Durante los años treinta publicó diversas obras en colaboración con Bioy Casares, su actividad literaria se amplió con la crítica literaria y con la traducción de autores como Virginia Woolf, Henri Michaux, William Faulkner.

Fue bibliotecario en Buenos Aires de 1937 a 1945, conferenciante y profesor de literatura inglesa en la Universidad de Buenos Aires y director de la Biblioteca Nacional de Argentina desde 1955 hasta 1974. Ganó el Premio Formentor (1961), y el Premio Miguel de Cervantes (1979).

Su obra narrativa se compone de los siguientes títulos: Historia universal de la infamia (1935), El jardín de los senderos que se bifurcan (1942), Ficciones (1944), El Aleph (1949), La muerte y la brújula (1951), El informe de Brodie (1970), El libro de arena (1975), 25 de agosto, 1983 (1983).

En el género poético, escribió: Fervor de Buenos Aires (1923), Luna de enfrente (1925), Cuaderno San Martín (1929), Poemas (1943), El hacedor (1960), Elogio de la sombra (1969), El oro de los tigres (1972), Historia de la noche (1976), Los conjurados (1985), entre otros.

De sus ensayos, destacamos Textos recobrados (1929), Inquisiciones (1925), Historia de la eternidad (1936), Antología personal (1961), El libro de los seres imaginarios (1968), Siete noches (1980), Biblioteca personal (1986) (RUIZA; FERNÁNDEZ; TAMARO, 2004a).

La producción de Borges se ubica en lo que los críticos consideran como "nueva narrativa hispanoamericana contemporánea", cuyos rasgos principales son: la aparición de temas urbanos, junto a temas rurales, variados problemas humanos, aparece la fantasía junto a la realidad - lo fantástico y lo maravilloso, mayor preocupación por la estructura y por el estilo, por influjo de las innovaciones técnicas de los grandes novelistas europeos y americanos (LÁZARO CARRETER; TUSÓN, 1990, p. 375).

De su obra narrativa, seleccionamos el cuento "Las ruinas circulares" (BORGES, 2000, p. 67-89), que hace parte del libro Ficciones (1944), con el objetivo de destacar su originalidad, estilo, tema y la concepción de literatura fantástica. Sobre esa obra, vale señalar que

En las páginas de este libro se despliega toda su [de Borges] maestría imaginativa, plasmada en cuentos como "La biblioteca de Babel", "El jardín de los senderos que se bifurcan" o "La lotería de Babilonia". También pertenece a este volumen "Pierre Menard, autor del Quijote", relato o ensayo (en Borges esos géneros suelen confundirse deliberadamente) en el que reformula con genial audacia el concepto tradicional de influencia literaria, así como su célebre cuento "La muerte y la brújula", en el que la trama policial se conjuga con sutiles apreciaciones derivadas del saber 
cabalístico, al que Borges dedicó devota atención. (RUIZA; FERNÁNDEZ; TAMARO, 2004a, s. p.).

Los cuentos de Borges, según apuntan Fernando Lázaro Carreter y Vicente Tusón (1990, p. 377), son de una originalidad sin par, pues a veces comienzan como si se tratara de un estudio erudito, en otras ocasiones, carecen de anécdota y se aproximan al tono del ensayo. Sus cuentos nos ponen en contacto con lo excepcional, con lo insólito.

"Las ruinas circulares" trata de la historia de un hombre que quiere crear a otro hombre y traerlo a la vida mediante el soñar. Tras una serie de intentos, logra su propósito. No obstante ese "hijo" soñado no es más que un fantasma, al cual el fuego no puede hacerle daño, y para que este no lo sepa y se sienta un hombre íntegro, el soñador borra de su memoria el tiempo de su aprendizaje. Ese "hijo" es enviado a otro templo, y al final del cuento, el soñador se da cuenta, durante un incendio, que él también es un sueño, porque al igual que "su hijo", las llamas no lo pueden herir.

Se puede dividir el cuento en cinco partes: 1 ) la llegada del forastero a un templo en ruinas, 2) la dedicación a la tarea de "dormir y soñar", 3) el fracaso de su intento de interpolar uno de sus discípulos en el mundo real, 4) el sueño y la creación de un "hijo" que es enviado a otro templo en ruinas, 5) el incendio y la comprensión de que el protagonista también es un sueño de otro personaje.

Todo el cuento presenta una estructura circular que conecta la primera parte con la última, y hay un énfasis en la temática de la narrativa que es el sueño, que se hace presente desde el epígrafe: "And if he left off dreaming about you...". Esa frase fue extraída de Alicia a través del espejo, del novelista inglés Lewis Carroll (1832-1892) y preanuncia el desenlace del cuento borgiano, al aludir al rey rojo del ajedrez, personaje clave en la citada obra, una vez que el rey supuestamente está soñando a la protagonista de la novela de Carrol, a quien los habitantes del mundo del espejo consideran una ilusión. La advertencia de Tweeledee - si te dejara de soñar ... desaparecerías- enoja a Alicia que afirma que es ella la que sueña al rey rojo, y no al revés, asegurando que no es la adormilada pieza de ajedrez que existe, en realidad, sino Alicia.

Así, se percibe desde el epígrafe, que se pone de manifiesto el juego de espejos, tan caro a Borges, en el cual el soñador sueña, pero también es soñado por alguien. De esa manera, en el cuento

"Las ruinas circulares" se sobresalen temas y motivos recurrentes y obsesivos en la poética de Borges: el tiempo circular, los espejos, los laberintos. La situación del protagonista refleja la de su hijo, ya que "su hijo irreal ejecutaba idénticos ritos, en otras ruinas circulares, aguas abajo; de noche no soñaba, o soñaba como lo hacen todos los hombres. [...]" (BORGES, 2000, p. 77).

Sus temas predilectos, según Lázaro Carreter y Tusón (1990, p. 377) son: la visión de la realidad como un laberinto incomprensible, la personalidad humana y sus extraños desdoblamientos, el destino del hombre y de la civilización, el tiempo, la eternidad, el infinito, la muerte. Se trata de una narrativa de perfiles metafísicos, intentando, por lo tanto, describir las propiedades, fundamentos, condiciones y causas primeras de la realidad, así como su sentido y finalidad. 
La estudiosa Camila Sofía Sanchez Quintana (2016, p. 5) señala la existencia de una espiral laberíntica y eterna en el cuento que estamos comentando:

[...] El hecho de que la historia del relato se repita constantemente y no se pueda divisar cuál es su principio o su fin genera el paralelismo con no poder acertar con la salida en un laberinto físico creando así un laberinto a través del tiempo cíclico en la historia. A su vez la contradicción de soñar y despertar constantemente genera la posibilidad de no lograr distinguir, tanto el lector como el mismo personaje, hasta donde es una vida real o simplemente un mundo creado. Así el límite entre sueño y realidad se pierde y desconcierta al lector aumentando la realización de un laberinto físico.

El laberinto entonces aparece como una temática recurrente en los escritos borgeanos, en "Las ruinas circulares", se duplica y pone de relieve el juego de espejos que también es uno de los rasgos de la poética borgeana.

En la segunda parte, lo que nos llama la atención es el propósito del protagonista, que viene expreso en uno de los pasajes más bonitos de la literatura hispanoamericana:

[...] Quería soñar un hombre: quería soñarlo con integridad minuciosa e imponerlo a la realidad. Ese proyecto mágico había agotado el espacio entero de su alma; si alguien le hubiera preguntado su propio nombre o cualquier rasgo de su vida anterior, no había acertado a responder. [...] El arroz y las frutas de su tributo eran pábulo suficiente para su cuerpo, consagrado a la única tarea de dormir y soñar. (BORGES, 2000, p. 70-71).

Ese firme propósito lleva el personaje a un fracaso inicial (tercera parte), al comprender que sus discípulos no se adecuaban a su propósito, siguió buscando "un alma que mereciera participar en el universo" (BORGES, 2016, p. 1), hasta soñar "un hombre íntegro, un mancebo, [...]. Noche tras noche, el hombre lo soñaba dormido" (BORGES, 2016, p. 2).

En la cuarta parte ocurre el nacimiento del hombre que el protagonista soñó: "Comprendió con cierta amargura que su hijo estaba listo para nacer. Tal vez impaciente. Esa noche lo besó por primera vez y lo envió al otro templo cuyos despojos blanquean río abajo, [...]" (BORGES, 2000, p. 77).

Al final, en la quinta parte, el personaje comprende que es una ilusión, la creación de otro:

[...] Caminó contra los jirones de fuego. Estos no mordieron su carne, éstos lo acariciaron y lo inundaron sin calor y sin combustión. Con alivio, con humillación, con terror, comprendió que él también era una apariencia, que otro estaba soñándolo. (BORGES, 2000, p. 79).

Como ya señalamos, aquí se configura la circularidad de la narrativa, que remite al principio, pues la historia del soñador se duplica y se confunde con la de su creación, el hijo que engendró en sueño e impuso a la realidad.

El tema del creador y criatura o padre e hijo se pone de relieve en el cuento de Borges, pues, tal cual un dios poderoso, el protagonista logra crear otro ser humano y lo inserta en las peripecias vividas en el relato.

Ese proceso de creador/criatura se concreta ad infinitum, una vez que el personaje central comprende que también fue criado por otro y 
todos esos seres pertenecen al plan de la magia, del ensueño, que están más allá de la realidad, "en la otra orilla", en un mundo que no es el que conocemos y en el cual nadie se muere.

Diferentemente del relato de Borges, en el cuento de Rulfo, se nota un tono realista de dolor, en el cual la muerte está presente, como un destino inexorable, como se podrá constatar en la secuencia de nuestro análisis.

De acuerdo con lo que expusimos, se puede observar que "Las ruinas circulares" es un cuento que se filia al género fantástico, en él están presentes algunos temas recurrentes de Borges tales como: la circularidad del tiempo, el juego de espejos que mezcla la vida del personaje soñador con la del personaje soñado, una vez que ambos son creaciones y deben su existencia a los sueños de terceros.

En ese cuento se percibe la entrada de la fantasía, de lo mágico y de lo insólito en la nueva narrativa hispanoamericana, se puede añadir que, en el cuento que comentamos, se nota la ruptura de las fronteras entre la ficción y la realidad, porque se plantea el problema del mundo y su representación, proporcionándonos una lectura muy incitante e inquietante, que posibilita otras lecturas y relecturas, lo que nos provoca un doble placer.

\section{Vida y muerte en "No oyes ladrar los perros"}

Juan Rulfo nació en Apulco, Jalisco, en 1918 y murió en Ciudad de México, en 1986. Sus únicas obras son el libro de cuentos El llano en llamas (1953) y la novela Pedro Páramo (1955) (RUIZA; FERNÁNDEZ; TAMARO, 2004b).

Con el propósito de establecer comparaciones entre el relato de Borges, anteriormente presentado, y una de las narrativas de Rulfo, elegimos la que se intitula "No oyes ladrar los perros", la que juntamente con otros dieciséis relatos, compone la obra El llano en llamas (RULFO, 1994, p. 145-150). Según Miguel Díez R. (2016, p. 6),

El tema general de El llano en llamas es la vida trágica del angustiado y desolado campesinado mexicano, tema que se va centrando recurrentemente en la violencia, la soledad, la degradación, la culpa, el fatalismo, y, desde luego, en la muerte, que penetra y está presente en cada cuento como su principal protagonista. Todos ellos temas reveladores de un sombrío pesimismo.

En todos los cuentos de la colección están presentes las voces campesinas, parcas y a la vez detalladas, que, reproducidas con toda la riqueza de entonación, con su particular y expresiva cadencia sintáctica, forman el tejido artístico de los cuentos, en el cual sólo por momentos se insertan las observaciones lacónicas del autor. El resultado es una peculiar mezcla de habla popular, la lírica y sombría expresión de un paisaje y de unas gentes desoladas y, en definitiva, la belleza y la profundidad emotiva propia del gran escritor mexicano.

Los críticos, según apunta Pedro Lasarte (1989, p. 101), al apreciar la obra del escritor Juan Rulfo, siguen dos direcciones: una que busca rescatar cierta visión histórica de un México rural y campesino; y otra que ha preferido ver en sus textos temas y personajes de un alcance más bien arquetípico y universal. Creemos que esas dos vertientes son complementarias en las producciones ficcionales de Rulfo. 
Los escritos del escritor mexicano se ubican en la nueva narrativa hispanoamericana y responden a una producción que superó el regionalismo tradicional y se insertó en un nuevo modo de ver y tratar la realidad de los hombres de América Latina:

Los escritores de la nueva novela hispanoamericana fueron conscientes de la consolidación alcanzada por la novela regionalista [...], pero no compartían el modo como éstas enfocaban la realidad, pues consideraban que lo hacían de una forma parcial y fragmentaria.

Los autores hispanoamericanos trataron de superar las concepciones objetivistas que habían caracterizado la novela anterior, dejaron de ceñirse a temas específicos (geografía, sistemas políticos, configuraciones sociales) y decidieron indagar en las estructuras profundas del lenguaje, considerando ahora una dimensión global y totalizante [...], de ahí que se plantearon ampliamente el concepto de realidad, los temas por abordar, la función del lenguaje utilizado y sobre todo, la necesidad de incursionar en la subjetividad de los personajes. (VARGAS, 2003, p. 110).

Aunque el estudioso Vargas se refiera solamente a la novela en su artículo, es posible considerar que sus observaciones sean aplicables a la narrativa hispanoamericana en general, sea cuento, como es nuestro caso, o novela.

Seguramente, los libros de Rulfo hacen parte de esa nueva posición de los escritores de América Latina, que tienen como propuesta la de superar el regionalismo y asumir una conciencia escritural innovadora por medio del tono humorístico, paródico o satírico, la proliferación de voces, la reformulación de la historia, la problematización de la escritura, de entre otros temas que buscan tratar de los problemas y singularidades de la realidad hispanoamericana.

"No oyes ladrar los perros", cuenta la historia de un padre que carga sobre sus hombros a su hijo herido, Ignacio, hacia un pueblo que se llama Tonaya. El ladrido de los perros indicaría la proximidad de ese pueblo, pero el padre no puede oírlo, porque su hijo le tapa sus orejas. Durante el trayecto, el padre va tambaleándose y tropezando por la oscuridad, y le dice a su hijo que él es malo, que sólo lo está cargando en consideración a su difunta madre. Cuando los dos llegan cerca del pueblo, el hijo suelta su cuerpo, "flojo, como si lo hubieran descoyuntado" (RULFO, 1994, p. 150). El padre desata sus dedos de su cuello y oye ladrar a los perros.

Los protagonistas de la historia son Ignacio y su padre. Este último es calificado como "viejo" en varios segmentos del relato: "El viejo se fue reculando hasta encontrarse con el paredón y se recargó allí, sin soltar la carga de los hombros. [...]" (RULFO, 1994, p. 145-146), "La cara del viejo, mojada de sudor, se llenó de luz." (RULFO, 1994, p. 148). De esa manera, el lector se entera de que el padre es mayor y casi no puede aguantar el peso de su hijo, que viene cargado sobre sus hombros.

Los rasgos principales de Ignacio son mencionados por su padre a lo largo del camino que los dos están recurriendo en dirección a Tonaya:

[...] Porque para mí usted ya no es mi hijo. He maldecido la sangre que usted tiene de mí. [...] Lo dije desde que supe que usted andaba trajinando por los caminos, viviendo del robo y matando gente... Y gente buena. Y si no, allí está mi compadre Tranquilino. El que lo bautizó a usted. El que le dio su nombre. A él le tocó la mala suerte de encontrarse con usted. Desde entonces dije: "Ese no puede ser mi hijo." (RULFO, 1994, p. 148-149).

Memorare, Tubarão, v. 8, n. 1, jan./jun. 2021. ISSN: 2358-0593 
En su habla, el padre deja muy claro que su hijo es malo, que asesinó a varias personas, incluso a su padrino, Tanquilino, y lo desprecia por eso, sin embargo, lo carga en sus hombros, pues no puede abandonarlo. La bondad del padre contrasta con la crudeza y las malas acciones de Ignacio, que paradójicamente, se parece a un niño, pues cuando los hijos aún son menores, son cargados por sus padres. El instinto paternal, el deber de padre hacen con que el "viejo" no abandone a su hijo herido y el relato se llena de una belleza poética, cuando las dos figuras se unifican:

[...] la imagen es poderosa y lo dice todo: los dos hombres forman un sólo cuerpo, una figura contrahecha en la que el que va "arriba" no puede caminar y el que va "abajo" no puede ver. El desolado y hostil paisaje, que parece dibujado con trazos expresionistas, también divide el mundo en dos partes: la espectral luz de la luna allá arriba, la tierra envuelta en sombras allá abajo. (OVIEDO, 2012, p. 69).

El cuento puede ser interpretado como un juego de antítesis en el cual se oponen padre (bueno) $\times$ hijo (malo), luna $\times$ tierra, arriba (la figura del hijo) $\times$ abajo (la figura del padre), ver (el hijo) $\times$ no ver $(\mathrm{el}$ padre), luz $\times$ oscuridad. Y estos pares antitéticos a la vez que se oponen, se vuelven también complementarios, ya que uno no puede existir sin el otro. Hasta el tratamiento del padre hacia su hijo -usted, en el momento en que le dice que no es más su hijo-y tú, cuando vuelve a apiadarse de él, a quererle bien, marcan el proceso antitético y complementario que se desarrolla durante la historia narrada.

Rita Gnutzmann (1972, p. 328) afirma que "No oyes ladrar los perros" se compone de escenas dramáticas dialogadas, como se puede observar en este pasaje del cuento:

-Mira a ver si ya ves algo. 0 si oyes algo. Tú que puedes hacerlo desde allá arriba, porque yo me siento sordo.

-No veo nada.

-Peor para ti, Ignacio.

-Tengo sed.

-¡Aguántate! Ya debemos estar cerca. Lo que pasa es que ya es muy noche y han de haber apagado la luz en el pueblo. Pero al menos debías de oír si ladran los perros. Haz por oír.

-Dame agua,

-Aquí no hay agua. No hay más que piedras. Aguántate. Y aunque la hubiera, no te bajaría a tomar agua. Nadie me ayudaría a subirte otra vez y yo solo no puedo.

-Tengo mucha sed y mucho sueño.

-Me acuerdo cuando naciste. Así eras entonces. [...] (RULFO, 1994, p. 149).

El diálogo tiene un efecto escénico y en el fragmento transcrito, se notan el cansancio del padre y la debilidad del hijo, que ya está casi muriéndose. De ese modo, ese pequeño trozo del cuento sintetiza la imagen del dolor y de la impotencia del padre que no puede hacer nada más que seguir cargando a su hijo, deseando llegar a Tonaya para que allá encuentre a un médico o alguien que pueda salvarle.

José Miguel Oviedo (2012, p. 68-69) considera que el cuento "No oyes ladrar los perros" es extraordinario, un ejemplo paradigmático del arte de Rulfo y agrega que se trata de

una conmovedora parábola de amor paternal, [...]. La enorme concentración dramática que alcanza el texto no sólo se debe a su 
brevedad, sino a la forma austera de su composición; los sucesos son mínimos, pues todo se reduce a la contemplación de esa imagen física de dos cuerpos entrelazados en su penosa marcha nocturna, cada uno con su propia agonía, pero con un doloroso lazo común: el de padre e hijo. El narrador nos coloca, en un arranque in medias res, ante una situación que prácticamente no cambia -sólo empeora-y que es intolerable. [...]

El proceso antitético a que ya aludimos también se manifiesta en la inversión de las relaciones entre padre e hijo, puesto que, los hijos serían los que deberían ayudar a sus padres, mantenerlos y cuidarlos. En el cuento, se percibe que "los hijos son una 'carga' para los padres" y la historia se concreta en una "alegoría sin duda trágica y desgarradora" (OVIEDO, 2012, p. 69).

Así, el relato de Rulfo se configura en una narrativa impar en la cual el amor de un padre por su hijo se expresa en un acto de piedad, en un medio donde predomina el rencor, el desprecio, y el fiero olvido, conforme afirma William H. Katra (1990, p. 191).

Al contrario de lo que ocurre con padre e hijo en la historia de Borges, en Rulfo se observa el infierno del dolor de los que carecen de esperanza, en medio a una realidad de violencia y desesperación en la que se denuncia un mundo salvaje, impiedoso, con una tonalidad realista, exasperante, que culmina con un desenlace trágico.

En "Las ruinas circulares", se percibe un tratamiento diverso en la relación del padre con su hijo, porque los dos son inmortales y pertenecen a una realidad distinta, que se ubica en lo extraordinario, en lo insólito, en el cual no hay muerte y cada personaje debe su existencia al ensueño de un otro y así sucesivamente.

Al final del cuento, es posible comprender que sobreviene la muerte del hijo y se reafirma la esperanza de vivir del padre a pesar de la tragedia que ocurre en su vida. Además, en "No oyes ladrar los perros", se destaca el drama de los campesinos aprisionados en un mundo de miseria, violencia, pero donde aún el amor existe y se impone en las relaciones de los personajes.

Aunque el modo de representar las figuras de padres e hijos sean diferentes en los dos cuentos, estos comprueban la genialidad tanto de Borges como de Rulfo, que se valen de estrategias discursivas oriundas del género fantástico y del regionalismo (que busca acercarse más a la realidad). Ambos resultan en expresiones de lo humano que siempre se sitúan entre lo real y lo imaginario, entre la ilusión y la realidad, como las dos caras de una misma moneda que hasta pueden oponerse, pero que se perpetúan como elementos complementarios.

\section{Conclusión}

En este trabajo, analizamos dos cuentos bastante distintos, el cuento "Las ruinas circulares", que pertenece al género fantástico, habla de un hombre que se propone a crear otro hombre e imponerlo a la realidad. Cuando logra su intento, percibe que él también es soñado por otro, una vez que el fuego no puede quemarlo. De esa manera, Borges hace un juego entre ficción y realidad, un hecho común en sus producciones, y que relativizan lo real y lo irreal, pues

¿Por qué nos inquieta que el mapa esté incluido en el mapa y las mil y una noches en el libro de Las mil y una noches? ¿Por qué nos inquieta que Don 
Quijote sea lector del Quijote, y Hamlet, espectador de Hamlet? Creo haber dado con la causa: tales inversiones sugieren que si los caracteres de una ficción pueden ser lectores o espectadores, nosotros, sus lectores o espectadores, podemos ser ficticios. En 1833, Carlyle observó que la historia universal es un infinito libro sagrado que todos los hombres escriben y leen y tratan de entender, y en el que también los escriben. (BORGES, 1960, p. 69).

$\mathrm{Al}$ leer el cuento de Borges, se mezclan mundos y representaciones distintos, el lector puede ser un ente de ficción y el personaje puede ser real. Siendo así, los textos de Borges, como es el caso de "Las ruinas circulares", discuten el tiempo, la eternidad, el infinito, la realidad y exigen un lector activo que vea la escritura como fuente de reflexión, de sorpresa y de goce. Así, un padre crea a su hijo y se da cuenta de que también fue creado por otro. La muerte no existe, pues la materia de la que son formados padre/hijo o creador/criatura es parte de una realidad mágica, donde todo es posible y nadie tiene fin, perpetuándose indefinidamente.

El cuento de Rulfo plantea el drama de un padre que, en tierras mexicanas, tiene que cargar a su hijo herido hasta un pueblo donde pueda recibir atención y cuidados. Es un texto que hace parte de la nueva narrativa contemporánea, que trata del hombre hispanoamericano y sus problemas, como la literatura regionalista, pero va más allá de eso, porque se pone de relieve el mundo interior de los personajes y las distintas voces narrativas que retratan el drama humano en un mundo marcado por la desesperación, la pobreza e infelicidad, pero lleno de sentimientos, de piedad y de una mirada llena de humanidad hacia los personajes, adquiriendo un carácter universal.

Los dos cuentos, por lo tanto, son ejemplos magníficos de la narrativa contemporánea, que señala los conflictos y la problemática que impregnan las relaciones familiares y recrean la realidad de modos distintos, pero a la vez, son capaces de instigar y agradar a los lectores de hoy y de todas las épocas, al tratar de la temática padre e hijo de modo distinto, y a la vez, complementario, porque ilusión y realidad se interconectan y forman parte intrínseca en todo lo que dice respeto al ser humano ficcional o de carne y hueso.

\section{Referencias}

BORGES, J. L. Otras inquisiciones. 2. ed. Buenos Aires: Emecê Editores, 1960.

BORGES, J. L. Las ruinas circulares. In: BORGES, J. L. Ficciones. Buenos Aires: Emecé, 2000, p. 67-79.

DÍEZ R., M. Cuento breve recomendado: “No oyes ladrar los perros”. In: Narrativa breve. Cuentos y microrrelatos. Teoría Literaria, entrevistas, corrección de estilo. p. 1-7. http://narrativabreve.com/2013/12/cuento-juan-rulfo-no-oyes-ladrarperros.html. Acesso em: $08 \mathrm{dez} .2016$.

GNUTZMANN, R. Perspectivas narrativas de El llano en llamas, de Juan Rulfo. Anales de Literatura Hispanoamericana, (1): 321-336, 1972. Disponível em: https://revistas.ucm.es/index.php/ALHI/article/view/ALHI7272110321A/2 5212. Acesso em: 18 ago. 2020. 
JORGE LUIS BORGES. Biografía.

http://www.cervantes.es/bibliotecas_documentacion_espanol/biografias/nue va_york_jorge_luis_borges.htm. Acesso em: 07 dez. 2016.

KATRA, W. H. No oyes ladrar los perros: La excepcionalidad y el fracaso. Revista Iberoamericana, n. 56: 179-191, 1990. Disponível em: https://revistaiberoamericana.pitt.edu/ojs/index.php/Iberoamericana/article/view/4676/4 840. Acesso em: 18 ago. 2020.

LASARTE, P. "No oyes ladrar los perros" de Juan Rulfo: peregrinaje hacia el origen. Inti:

Revista de literatura hispánica, n. 29-30, 1989, p. 101-118. Disponível em: https://digitalcommons.providence.edu/cgi/viewcontent.cgi?article=1453\&c ontext=inti. Acesso em: 18 ago. 2020.

LÁZARO CARRETER, F.; TUSÓN, V. Literatura española. Madrid: Anaya, 1990.

OVIEDO, J. M. Historia de la literatura hispanoamericana. 4. De Borges al presente. Madrid: Alianza Editorial, 2012.

RUIZA, M.; FERNÁNDEZ, T.; TAMARO, E. Biografia de Jorge Luis Borges. En: Biografías y Vidas. La enciclopedia biográfica en línea. Barcelona (España), 2004a.

Recuperado de https://www.biografiasyvidas.com/biografia/b/borges.htm el 18 de agosto de 2020.

RUIZA, M.; FERNÁNDEZ, T.; TAMARO, E. Biografía de Juan Rulfo. En: Biografías y Vidas. La enciclopedia biográfica en línea. Barcelona (España), 2004b. Recuperado de https://www.biografiasyvidas.com/biografia/r/rulfo.htm el 18 de agosto de 2020.

RULFO, J. No oyes ladrar los perros. In: RULFO, J. El llano en llamas. 2. ed. México: Fondo de Cultura Económica, 1994, p. 145-150.

SAINZ BORGO, K. Ocho libros sobre el padre en la literatura contemporánea. Vozpópuli. Disponível em: https://www.vozpopuli.com/altavoz/cultura/librospadre_0_1117988936.html. Acesso em: 10 mai. 2020.

SANCHEZ QUINTANA, C. S. Espiral laberíntica y eterna. Análisis del tiempo cíclico como laberinto en Las ruinas circulares de Jorge Luis Borges, p. 1-8. Disponível em: https://fido.palermo.edu/servicios_dyc/blog/docentes/trabajos/26196_9095 8.pdf. Acesso em: $08 \mathrm{dez} .2016$.

VARGAS, J. Á. Superación del regionalismo y conciencia escritural en la novela centroamericana contemporánea. Inter Sedes, vol. IV, (6-2003), p. 109-124.

Artigo enviado em: 17/10/2020. Aprovado em: 30/11/2021. 